\author{
Military Technical College \\ Kobry El-Kobbah, \\ Cairo, Egypt
}

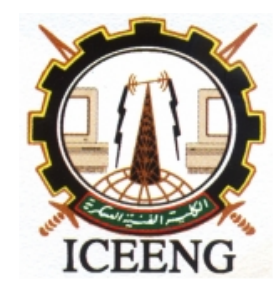

\section{$7^{\text {th }}$ International Conference on Electrical Engineering ICEENG 2010}

\title{
Nonlinear Control based Sliding Modes for HVDC Light System Behavioral Enhancement under Parameters Uncertainties
}

By
H. S. Ramadan*
M. Petit**
H. Siguerdidjane**
R. Kaczmarek**

\section{Abstract:}

Two different nonlinear control methodologies based robust Sliding Mode Control (SMC) for HVDC Light ${ }^{\mathrm{TM}}$ transmission system's possessing parameters uncertainties are proposed. Appropriate feedback signals are formulated to control the active and reactive powers towards their specified set point values and to govern the DC link voltage to its desired value. The first controller maintains the active and reactive powers to their anticipated rated values using their corresponding reference signals directly. The other uses an additional auxiliary controller based proportional-integral (PI) controller or the two degrees of freedom proportional-integral-derivative (2DOF-PID) controller to govern the DC voltage and to generate the necessary direct and quadrature currents reference signals that are inserted to the main controller based SMC in order to control the corresponding powers. The controllers' gains are adjusted using Lyapunov method to guarantee zero tracking error in order to ensure the system's stability. The feasibility and effectivity of both control techniques are evaluated in terms of performance enhancement and their robustness are compared under parameters uncertainties and verified for different DC link lengths using MATLAB ${ }^{\odot}$.

\section{Keywords:}

Lyapunov Functions, Parameters Uncertainties, Robustness, SMC, and VSC-HVDC

* Assistant Lecturer in Zagazig University, Zagazig, Egypt and a PhD student in Ecole Supérieure d'Electricité (SUPELEC), Gif sur Yvette, France.

** Ecole Supérieure d'Electricité (SUPELEC), Gif sur Yvette, France. 


\section{Introduction:}

A worldwide trend in the development of power systems is to build interconnections with the goal to offer technical, economical and environmental benefits. Interconnections via $\mathrm{AC}$ transmission systems suffer from several disadvantages such as reactive power control, difficulty of controlling power flow and guaranteeing stability.

The recent decades are witnessing significant development in High Voltage Direct Current (HVDC) electrical power transmission systems, which are continuously innovated by utilizing state-of-the-art power electronic devices. As a member of these advanced systems, voltage source converter-based HVDCs (VSC-HVDC's), which are known commercially HVDC Light, have the ability to rapidly control the transmitted active power, and also to independently exchange reactive power with transmission systems. The first VSC-HVDC system was installed in 1997 in Hellsjön in Sweden, with a power rating of $3 \mathrm{MW}$ and $\pm 10 \mathrm{kV}$ voltage with the goal of studying the viability of the technology [1,2]. A number of potential advantages of HVDC Light, such as its capability of feeding power into passive networks with no local power generation, supplying a load on an island, connecting of off-shore wind farms or oil drilling platforms into the mainland electrical network, enabling fast control of active and reactive power independently with high bandwidth which allows active power flow to be quickly reversed, and being used for underground transmission or distribution systems within congested cities in addition to its desirable feature in enabling short-term transactions in the electric power markets, are mentioned [3-7]. HVDC Light with a suitable control scheme can offer an alternative means to enhance transient stability, to improve power oscillations damping, and to provide voltage support [8]. Moreover, when compared with the conventional HVDC, it mitigates greatly the harmonics in AC currents and $\mathrm{AC}$ voltages and improves the AC systems' power factors [9]. These advantages are owing to the use of fully controllable power electronics devices such as IGBT and GTO which employs self-commutation technique and allows the use of VSCs in HVDC system in a frequency range of $1-2 \mathrm{kHz}[1,2]$ with much lower harmonic distortion than the conventional HVDC systems although with power losses (4-5\%) that gives it a promising future [10].

Formerly, effective control schemes such as classical control, optimal control and digital control have been applied for damping power system oscillations and improving its dynamic performance [11-13]. However, these approaches are mostly based on approximate linearization models around a specific operating point. Nowadays, to get rid of the difficulties during abnormal operating conditions particularly in the presence of parametric uncertainties, disturbances and faults, the use of advanced nonlinear controls (NLCs) such as adaptive control, self-tuning control, variable structure control, feedback linearization (FL) technique and artificial intelligence-based control design methods have been of the most promising application areas of automatic control [14] 
that were applied to improve the power systems transient stability. The adaptive controller [15] provides real-time identification of system dynamics and then adjusts the controller parameters based on identified models. Therefore, the overall system's performance mainly relies on the identification's accuracy. The self-tuning controller [16] implements the system output tracking and handles the ambiguities and the uncertainties in the system parameters. The variable structure controller [17] provides robustness and insensitivity to system parameter variations and constrains the system trajectory to a sliding mode. The FL technique [18] based on differential geometric theorem has also been applied to solve various nonlinear control problems concerning power system stability.

In this paper, the authors propose nonlinear SMC to reach the unity power factor at both AC sides of the HVDC by maintaining the active and reactive power flow to their set points of $200 \mathrm{MW}$ and zero respectively. Furthermore, the DC link voltages of both sides are adjusted to steady state reference values of $300 \mathrm{kV}$. For doing so, two methodologies have been applied. Firstly, the active and reactive powers have been controlled via SMC by using their reference signals directly. Secondly, a supplementary PI controller or an extra 2DOF-PID controller has been employed to govern the DC voltage and to generate the $d-q$ current reference signals. Then, the outcomes have been exploited to control the corresponding active and reactive powers via SMC. The validity of both control strategies has been verified using simulations under parametric uncertainties to evaluate the dynamic performance. Finally, both control techniques have been compared.

In this paper, a concise definition for nonlinear SMC control methodology is introduced in Section 2. In Section 3, the HVDC Light system's steady state mathematical model is briefly described. Section 4 argues the structure of the designed nonlinear feedback controller using the two different techniques based SMC methodology with and without the proposed auxiliary controllers. Next, in Section 5, simulation results are given for exhibiting the controllers' performance and verifying their robustness. Finally, conclusions are drawn in Section 6.

\section{Sliding Mode Control:}

SMC have been proved sound and successful in control problems. The SMC, developed in the early 1950 s by V. Utkin, has been recognized as one of the efficient tools to design robust controllers for complex high-order nonlinear dynamic plants operating under various uncertainty conditions. The major advantage of sliding mode is its low sensitivity to parameter variations and disturbances which relaxes the necessity of exact modeling [19].

SMC enables the decoupling of the overall system motion into independent partial components of lower dimension, which reduces the complexity of feedback design. The 
SMC implies that control actions are discontinuous state functions which may easily be implemented by conventional power converters with "on/off"' as the only admissible operation mode. However, the implementation of the SMC may be obstructed by an undesirable phenomenon of oscillations with finite frequency and amplitude, which is known as 'chattering'. This harmful phenomenon, chattering, is caused by unmodeled dynamics or discrete time implementation, and oftenly leads to undesirable results. However, for some applications, the chattering may be unavoidable due to certain characteristics of the systems. Usually, having higher switching frequencies of actuators means better properties of systems. But, in power electronics, high frequency may cause high losses. Thus, making use of continuous functions such as saturation, sigmoid and hyperbolic functions leads to overcoming the chattering phenomena and enhancing the system's stability [19-22].

The idea behind the SMC is to derive the system state trajectory and to force the error signal to approach the sliding surface, $\mathrm{S}(\mathrm{t})=0$, and then slide along it until reaching the desired final value as depicted in Fig. 1.

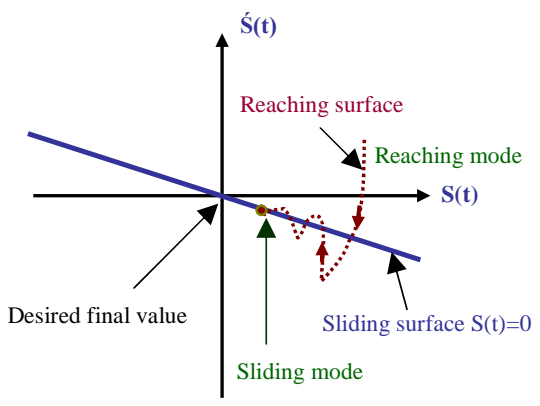

Figure (1): Graphical interpretation of SMC

\section{HVDC Light System's Mathematical Model:}

The design of HVDC Light system's controller is mainly based on its mathematical model. However, this real physical system is easy to be influenced by external or internal interference of uncertainties. The basic HVDC Light transmission system has usually the scheme sketched in Fig. 2 [23-29]. The steady state analysis of the HVDC Light system is significantly simplified if assuming: (i) The AC sources delivers, at the converter terminal, a sinusoidal voltage waveform with constant amplitude and frequency with balanced three phases. (ii) All voltages and currents harmonics produced by converter are filtered out and are not passed on to the AC system. (iii) The converter transformer has neither resistance nor magnetizing impedance. (iv) The converter is lossless with ideal valves. (v) No ripples in DC voltages and currents.

In Fig. 2, the active powers $\left(\mathrm{P}_{1}\right.$ and $\left.\mathrm{P}_{2}\right)$ and the reactive powers $\left(\mathrm{Q}_{1}\right.$ and $\left.\mathrm{Q}_{2}\right)$ respectively have been controlled to their desired values to approach the anticipated unity power factor besides governing the voltage of both DC link sides, $U c_{1}$ and $U c_{2}$, to 
the rated values keeping into account the DC link power losses and voltage drop. The active power control should be bidirectional.

The continuous-time equivalent HVDC Light system's model has been depicted in Fig. 3 [25-29]. The VSC is coupled with AC networks via equivalent impedances $\mathrm{R}_{\mathrm{L} 1}+\mathrm{j} \mathrm{X}_{\mathrm{L} 1}$ and $\mathrm{R}_{\mathrm{L} 2}+\mathrm{jX} \mathrm{X}_{\mathrm{L} 2}$. DC shunt capacitors, $\mathrm{C}_{1}$ and $\mathrm{C}_{2}$, are used across the $\mathrm{DC}$ side of the VSC to boost the DC voltage, mitigate the impulse current and attenuate the DC sides' harmonics.

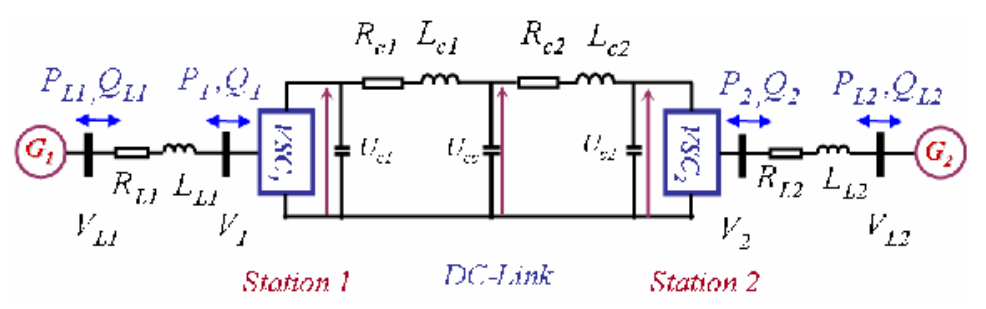

Figure (2): HVDC Light system's scheme

According to Fig. 3, the voltage drop in each phase 'ph' for both sides has been expressed by the following:

$\mathrm{L}_{\mathrm{L} 1} \frac{\mathrm{di}_{\mathrm{L} p \mathrm{ph}}}{\mathrm{dt}}+\mathrm{R}_{\mathrm{L} 1} \mathrm{i}_{\mathrm{L} 1 \mathrm{ph}}=\mathrm{v}_{\mathrm{L} 1 \mathrm{ph}}-\mathrm{v}_{1 \mathrm{ph}}$
$\mathrm{L}_{\mathrm{L} 2} \frac{\mathrm{di}_{\mathrm{L} 2 \mathrm{ph}}}{\mathrm{dt}}+\mathrm{R}_{\mathrm{L} 2} \mathrm{i}_{\mathrm{L} 2 \mathrm{ph}}=\mathrm{v}_{2 \mathrm{ph}}-\mathrm{v}_{\mathrm{L} 2 \mathrm{ph}}$

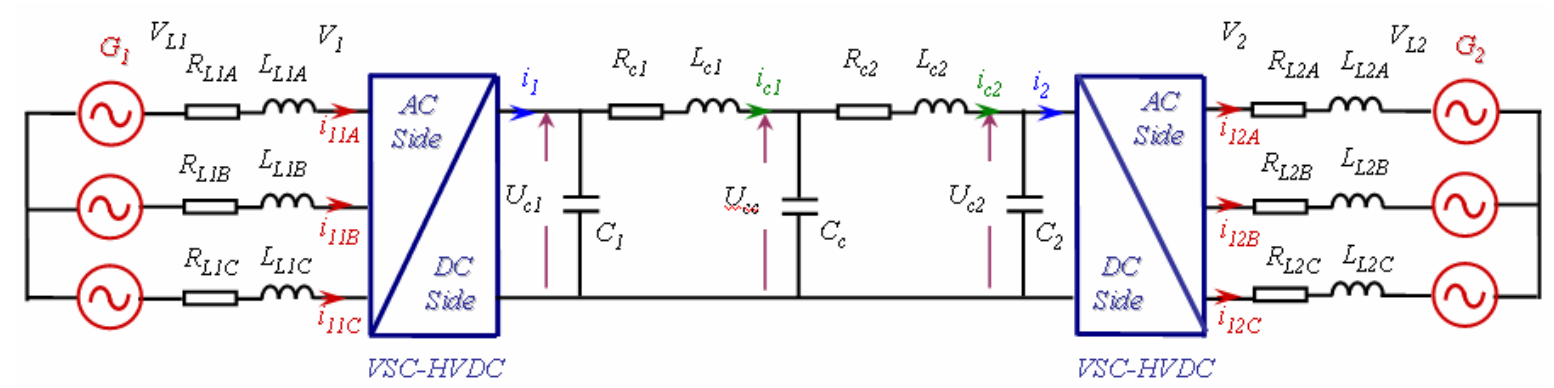

Figure (3): Continuous-time VSC-HVDC model

As displayed in Fig. 4, if a balanced three phase system rotating at a pulsation $\omega_{1}$ with $\theta_{1}=\omega_{1} \mathrm{t}$, and a rotating frame $d_{1}-q_{1}$ initially oriented on $\theta_{1}$ and given a duty cycle $\mathrm{r}_{1}$, the following set of equations has been given [25]:

$$
\left\{\begin{array}{l}
\overrightarrow{\mathrm{v}_{\mathrm{L} 1}}=\mathrm{V}_{\mathrm{L} 1} \mathrm{e}^{\mathrm{j} \gamma_{1}}=\mathrm{V}_{\mathrm{L} 1} \cos \left(\gamma_{1}\right)+\mathrm{j} \mathrm{V}_{\mathrm{L} 1} \sin \left(\gamma_{1}\right)=\mathrm{V}_{\mathrm{Lld}}+\mathrm{jV}_{\mathrm{Llq}} \\
\overrightarrow{\mathrm{v}_{1}}=\mathrm{V}_{1} \mathrm{e}^{\mathrm{j} \psi_{1}}=\mathrm{V}_{1} \cos \left(\psi_{1}\right)+\mathrm{j}_{1} \sin \left(\psi_{1}\right)=\mathrm{V}_{1 \mathrm{~d}}+\mathrm{jV}_{\mathrm{lq}} \\
\overrightarrow{\mathrm{i}_{\mathrm{L} 1}}=\mathrm{I}_{\mathrm{L} 1} \mathrm{e}^{\mathrm{j} \varphi_{1}}=\mathrm{I}_{\mathrm{L} 1} \cos \left(\varphi_{1}\right)+\mathrm{j} \mathrm{I}_{\mathrm{L} 1} \sin \left(\varphi_{1}\right)=\mathrm{I}_{\mathrm{Lld}}+\mathrm{jI} \mathrm{I}_{\mathrm{Llq}}
\end{array}\right.
$$

Furthermore, 
$\overrightarrow{\mathrm{v}_{1}}=\mathrm{r}_{1} \frac{\mathrm{U}_{\mathrm{c} 1}}{2} \mathrm{e}^{\mathrm{j} \psi_{\mathrm{w} 1}}=\mathrm{V}_{1 \mathrm{dw}} \frac{\mathrm{U}_{\mathrm{c} 1}}{2}+\mathrm{jV}_{\mathrm{lqw}} \frac{\mathrm{U}_{\mathrm{c} 1}}{2}$

$\mathrm{V}_{\mathrm{ldw}}=2 \frac{\mathrm{v}_{\mathrm{ld}}}{\mathrm{U}_{\mathrm{cl}}}$ and $\mathrm{V}_{\mathrm{lqw}}=2 \frac{\mathrm{v}_{\mathrm{lq}}}{\mathrm{U}_{\mathrm{cl}}}$

Where $\mathrm{v}_{\mathrm{L} 1 \mathrm{~d}}$ and $\mathrm{v}_{\mathrm{L} 1 \mathrm{q}}$ are the $d-q$ voltage components of the AC source calculated using Park transformation, $\mathrm{i}_{\mathrm{L} 1 \mathrm{~d}}$ and $\mathrm{i}_{\mathrm{L} 1 \mathrm{q}}$ are the $d-q$ current components flowing in the AC line, $\mathrm{v}_{1 \mathrm{~d}}$ and $\mathrm{v}_{1 \mathrm{q}}$ are the $d-q$ voltage components on the AC side of the HVDC Light system, moreover, the dimensionless $d-q$ components, $\mathrm{V}_{1 \mathrm{dw}}$ and $\mathrm{V}_{1 \mathrm{qw}}$, represent the relation of both $\mathrm{v}_{1 \mathrm{~d}}$ and $\mathrm{v}_{1 \mathrm{q}}$ with $\mathrm{U}_{\mathrm{c} 1}$.

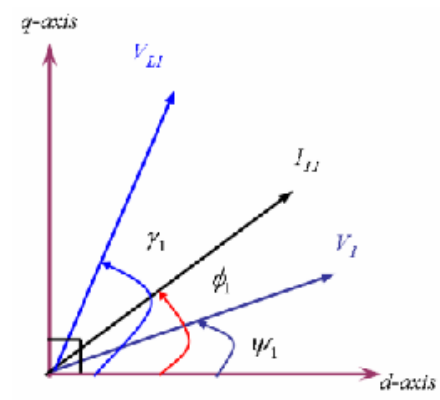

Figure (4): $d_{1}-q_{1}$ phasor diagram

Applying the power equality on both sides of the rectifier:

$\mathrm{U}_{\mathrm{cl}} \mathrm{I}_{1}=3 \mathrm{~V}_{1} \mathrm{I}_{\mathrm{L} 1} \cos \left(\psi_{1}-\varphi_{1}\right)$

$\mathrm{U}_{\mathrm{cl}} \mathrm{I}_{1}=0.75 \mathrm{U}_{\mathrm{cl}}\left(\mathrm{v}_{\text {ldw }} \mathrm{i}_{\text {Lld }}+\mathrm{v}_{\text {lqw }} \mathrm{i}_{\mathrm{Llq}}\right)$

By analogy, the equations of both inverter sides have been deduced. Then, the system's global state space presentation that indicates the relationships among the systems' different variables is expressed as [25-29]:

$\left\{\begin{array}{l}\mathrm{d}=[\mathrm{A}] \mathrm{x}+\mathrm{g}(\mathrm{x}) \mathrm{u}+[\mathrm{R}] \mathrm{z} \\ \mathrm{y}=\mathrm{h}(\mathrm{x}, \mathrm{u}) \mathrm{x}\end{array}\right.$

where, $\mathrm{x}, \mathrm{u}, \mathrm{z}$ and $\mathrm{y}$ refer to state variables, control signals, $d-q$ components of the AC source calculated using Park transformation and the output power signals (active and reactive) respectively.

$$
\begin{aligned}
& \mathrm{x}_{1, \ldots 9}=\left[\mathrm{i}_{\mathrm{Lld}}, \mathrm{i}_{\mathrm{Llq}}, \mathrm{u}_{\mathrm{c} 1}, \mathrm{i}_{\mathrm{cl}}, \mathrm{u}_{\mathrm{cc}}, \mathrm{i}_{\mathrm{c} 2}, \mathrm{u}_{\mathrm{c} 2}, \mathrm{i}_{\mathrm{L} 2 \mathrm{~d}}, \mathrm{i}_{\mathrm{L} 2 \mathrm{q}}\right]^{\mathrm{T}} \\
& \mathrm{z}_{1, \ldots 4}=\left[\mathrm{v}_{\mathrm{Lld}}, \mathrm{v}_{\mathrm{Llq}}, \mathrm{v}_{\mathrm{L} 2 \mathrm{~d}}, \mathrm{v}_{\mathrm{L} 2 \mathrm{q}}\right]^{\mathrm{T}} \\
& \mathrm{u}_{1, \ldots 4}=\left[\mathrm{v}_{1 \mathrm{ld}}, \mathrm{v}_{1 \mathrm{lq}}, \mathrm{v}_{2 \mathrm{dw}}, \mathrm{v}_{\text {2qw }}\right]^{\mathrm{T}} \\
& \mathrm{y}_{1, \ldots 4}=\left[\mathrm{P}_{1}, \mathrm{Q}_{1}, \mathrm{P}_{2}, \mathrm{Q}_{2}\right]^{\mathrm{T}}
\end{aligned}
$$

The $[A], g(x),[R]$ and $h(x, u)$ matrices are printed out as: 


$$
\begin{aligned}
& {[\mathrm{A}]=\left[\begin{array}{ccccccccc}
\frac{-\mathrm{R}_{\mathrm{L} 1}}{\mathrm{~L}_{\mathrm{L} 1}} & \mathrm{w}_{1} & 0 & 0 & 0 & 0 & 0 & 0 & 0 \\
-\mathrm{w}_{1} & \frac{-\mathrm{R}_{\mathrm{L} 1}}{\mathrm{~L}_{\mathrm{L} 1}} & 0 & 0 & 0 & 0 & 0 & 0 & 0 \\
0 & 0 & 0 & \frac{-1}{\mathrm{C}_{1}} & 0 & 0 & 0 & 0 & 0 \\
0 & 0 & \frac{1}{\mathrm{~L}_{\mathrm{c} 1}} & \frac{-\mathrm{R}_{\mathrm{c} 1}}{\mathrm{~L}_{\mathrm{c} 1}} & \frac{-1}{\mathrm{~L}_{\mathrm{c} 1}} & 0 & 0 & 0 & 0 \\
0 & 0 & 0 & \frac{1}{\mathrm{C}_{\mathrm{c}}} & 0 & \frac{-1}{\mathrm{C}_{\mathrm{c}}} & 0 & 0 & 0 \\
0 & 0 & 0 & 0 & \frac{1}{\mathrm{~L}_{\mathrm{c} 2}} & \frac{-\mathrm{R}_{\mathrm{c} 2}}{\mathrm{~L}_{\mathrm{c} 2}} & \frac{-1}{\mathrm{~L}_{\mathrm{c} 2}} & 0 & 0 \\
0 & 0 & 0 & 0 & 0 & \frac{1}{\mathrm{C}_{2}} & 0 & 0 & 0 \\
0 & 0 & 0 & 0 & 0 & 0 & 0 & \frac{-\mathrm{R}_{\mathrm{L} 2}}{\mathrm{~L}_{\mathrm{L} 2}} & \mathrm{w}_{2} \\
0 & 0 & 0 & 0 & 0 & 0 & 0 & -\mathrm{w}_{2} & \frac{-\mathrm{R}_{\mathrm{L} 2}}{\mathrm{~L}_{\mathrm{L} 2}}
\end{array}\right]} \\
& \mathrm{g}(\mathrm{x})=\left[\begin{array}{ccccccccc}
\frac{-1}{2 \mathrm{~L}_{\mathrm{L} 1}} \mathrm{x}_{3} & 0 & \frac{3}{4 \mathrm{C}_{1}} \mathrm{x}_{1} & 0 & 0 & 0 & 0 & 0 & 0 \\
0 & \frac{-1}{2 \mathrm{~L}_{\mathrm{L} 1}} \mathrm{x}_{3} & \frac{3}{4 \mathrm{C}_{1}} \mathrm{x}_{2} & 0 & 0 & 0 & 0 & 0 & 0 \\
0 & 0 & 0 & 0 & 0 & 0 & \frac{-3}{4 \mathrm{C}_{2}} \mathrm{x}_{8} & \frac{1}{2 \mathrm{~L}_{\mathrm{L} 2}} \mathrm{x}_{7} & 0 \\
0 & 0 & 0 & 0 & 0 & 0 & \frac{-3}{4 \mathrm{C}_{2}} \mathrm{x}_{9} & 0 & \frac{1}{2 \mathrm{~L}_{\mathrm{L} 2}} \mathrm{x}_{7}
\end{array}\right]_{4^{*} 9}^{\mathrm{T}} \\
& {[R]=\left[\begin{array}{ccccccccc}
\frac{1}{\mathrm{~L}_{\mathrm{L} 1}} & 0 & 0 & 0 & 0 & 0 & 0 & 0 & 0 \\
0 & \frac{1}{\mathrm{~L}_{\mathrm{L} 1}} & 0 & 0 & 0 & 0 & 0 & 0 & 0 \\
0 & 0 & 0 & 0 & 0 & 0 & 0 & \frac{-1}{\mathrm{~L}_{\mathrm{L} 2}} & 0 \\
0 & 0 & 0 & 0 & 0 & 0 & 0 & 0 & \frac{-1}{\mathrm{~L}_{\mathrm{L} 2}}
\end{array}\right]_{4^{*} 9}^{\mathrm{T}}}
\end{aligned}
$$




$$
\mathrm{h}(\mathrm{x}, \mathrm{u})=\left[\begin{array}{ccccccccc}
\mathrm{v}_{1 \mathrm{~d}} & \mathrm{v}_{1 \mathrm{q}} & 0 & 0 & 0 & 0 & 0 & 0 & 0 \\
\mathrm{v}_{1 \mathrm{q}} & -\mathrm{v}_{1 \mathrm{~d}} & 0 & 0 & 0 & 0 & 0 & 0 & 0 \\
0 & 0 & 0 & 0 & 0 & 0 & 0 & \mathrm{v}_{2 \mathrm{~d}} & \mathrm{v}_{2 \mathrm{q}} \\
0 & 0 & 0 & 0 & 0 & 0 & 0 & \mathrm{v}_{2 \mathrm{q}} & -\mathrm{v}_{2 \mathrm{~d}}
\end{array}\right]_{4^{*} \mathrm{~g}}
$$

The active and reactive powers supplied to both AC sides of the HVDC system have been given by [25-29]:

$$
\begin{aligned}
& \mathrm{P}_{1}=1.5\left(\mathrm{v}_{1 \mathrm{~d}} \mathrm{i}_{\mathrm{Lld}}+\mathrm{v}_{1 \mathrm{q}} \mathrm{i}_{\mathrm{Llq}}\right) \\
& \mathrm{Q}_{1}=1.5\left(\mathrm{v}_{1 \mathrm{q}} \mathrm{i}_{\mathrm{Lld}}-\mathrm{v}_{1 \mathrm{~d}} \mathrm{i}_{\mathrm{Llq}}\right) \\
& \mathrm{P}_{2}=1.5\left(\mathrm{v}_{2 \mathrm{~d}} \mathrm{i}_{\mathrm{L} 2 \mathrm{~d}}+\mathrm{v}_{2 \mathrm{q}} \mathrm{i}_{\mathrm{L} 2 \mathrm{q}}\right) \\
& \mathrm{Q}_{2}=1.5\left(\mathrm{v}_{2 \mathrm{q}} \mathrm{i}_{\mathrm{L} 2 \mathrm{~d}}-\mathrm{v}_{2 \mathrm{~d}} \mathrm{i}_{\mathrm{L} 2 \mathrm{q}}\right)
\end{aligned}
$$

The design of robust nonlinear controllers based SMC is mandatory, after developing the system's steady state nonlinear mathematical model, for hopefully fulfilling the paper's objectives stated previously.

\section{Nonlinear Control Strategy:}

For nonlinear HVDC Light transmission systems, the attempt to design feedback control to cope with a wide range of model uncertainties leads to either a robust or an adaptive control problem.

For robust controllers design, feedback control laws based SMC are formulated for maintaining unity power factors at each HVDC's $A C$ side $\left(\mathrm{Q}_{1}\right.$ and $\mathrm{Q}_{2}$ are to be zeros), controlling the active power and governing the DC voltage of the HVDC Light system to their rated values of $200 \mathrm{MW}$ and $300 \mathrm{kV}$ respectively for the first side and $\left(200-\mathrm{P}_{\text {loss }}\right)$ MW and (300- $\left.\mathrm{V}_{\text {drop }}\right) \mathrm{kV}$ for the other taken the power flow direction into account.

Supposing the power delivered to station 2, the references of the outputs and states corresponding to the powers and DC voltages respectively are:

$\mathrm{y}_{1 \text { ref }}=200 \mathrm{MW}, \mathrm{y}_{2 \text { ref }}=0, \mathrm{y}_{3 \text { ref }}=200-\mathrm{P}_{\text {loss }} \mathrm{MW}, \mathrm{y}_{4 \text { ref }}=0, \mathrm{x}_{3 \mathrm{ref}}=300 \mathrm{kV}, \mathrm{x}_{7 \mathrm{ref}}=300-\mathrm{V}_{\text {drop }}$ $\mathrm{kV}$. Zero values are given for their derivatives. Where, $\mathrm{P}_{\text {loss }}$ and $\mathrm{V}_{\text {drop }}$ refer to the power loss and the voltage drop in the DC link respectively.

To design the SMC controller for which the control output $y_{i}$ tracks its reference $y_{\text {iref }}$ and the tracking errors $\varepsilon_{\mathrm{i}}$ approach zero when the time tends to infinity, two different controllers based SMC are supposed:

Controller (1): for which the SMC controller of each converter uses the active and reactive power reference signals directly as illustrated in Fig. 5. The sliding surfaces are represented by the error signals inserted to the proposed controller based SMC as:

$\varepsilon_{\mathrm{i}}(\mathrm{y})=\mathrm{y}_{\text {iref }}-\mathrm{y}_{\mathrm{i}}$

Noting that: $\mathrm{y}_{1}, \mathrm{y}_{2}, \mathrm{y}_{3}$ and $\mathrm{y}_{4}$ correspond to $\mathrm{P}_{1}, \mathrm{Q}_{1}, \mathrm{P}_{2}$ and $\mathrm{Q}_{2}$ respectively. 
To ensure stability while designing the nonlinear controller, an appropriate positive definite Lyapunov energy function candidate $\mathrm{V}(\mathrm{y})=0.5 \varepsilon^{2}(\mathrm{y})$ has been chosen, its time derivative is $\&(y)=\varepsilon(y) \& y)$. In order to verify that $\&(y)$ is always negative and to avoid chattering issues, one of the following set of functions with positive tuning constants $\mathrm{K}_{1}$ and $\mathrm{K}_{2}$ can be selected:

$\& \mathrm{y})=\left\{\begin{array}{l}-\mathrm{K}_{1} \operatorname{sign}(\varepsilon(\mathrm{y}))-\mathrm{K}_{2} \varepsilon(\mathrm{y}) \\ -\mathrm{K}_{1} \operatorname{sat}(\varepsilon(\mathrm{y}))-\mathrm{K}_{2} \varepsilon(\mathrm{y}) \\ -\mathrm{K}_{1} \tanh (\varepsilon(\mathrm{y}))-\mathrm{K}_{2} \varepsilon(\mathrm{y})\end{array}\right.$

For simplicity, equal positive tuning gains have been proposed in Eq. (18), thus, $\mathrm{K}_{1}=\mathrm{K}_{2}=\mathrm{K}$. The stability has been guaranteed for any positive tuning gains. Those gains dominantly control the speed of convergence. The more positive the tuning gains have been chosen, the more negative definite $\&(y)$ will be, and the faster the system behavior in catching its references' variation that leads to a shorter time response. Theoretically, a proper choice of the tuning gains which equals 100 results in two to three cycles of transient response of an input frequency of 50 or $60 \mathrm{~Hz}$ which is acceptable for power system applications.

An expanded deduction of the feedback control signals design has been given explicitly in Appendix A. Then, the controller's robustness in accordance with parameters' uncertainties has been verified.

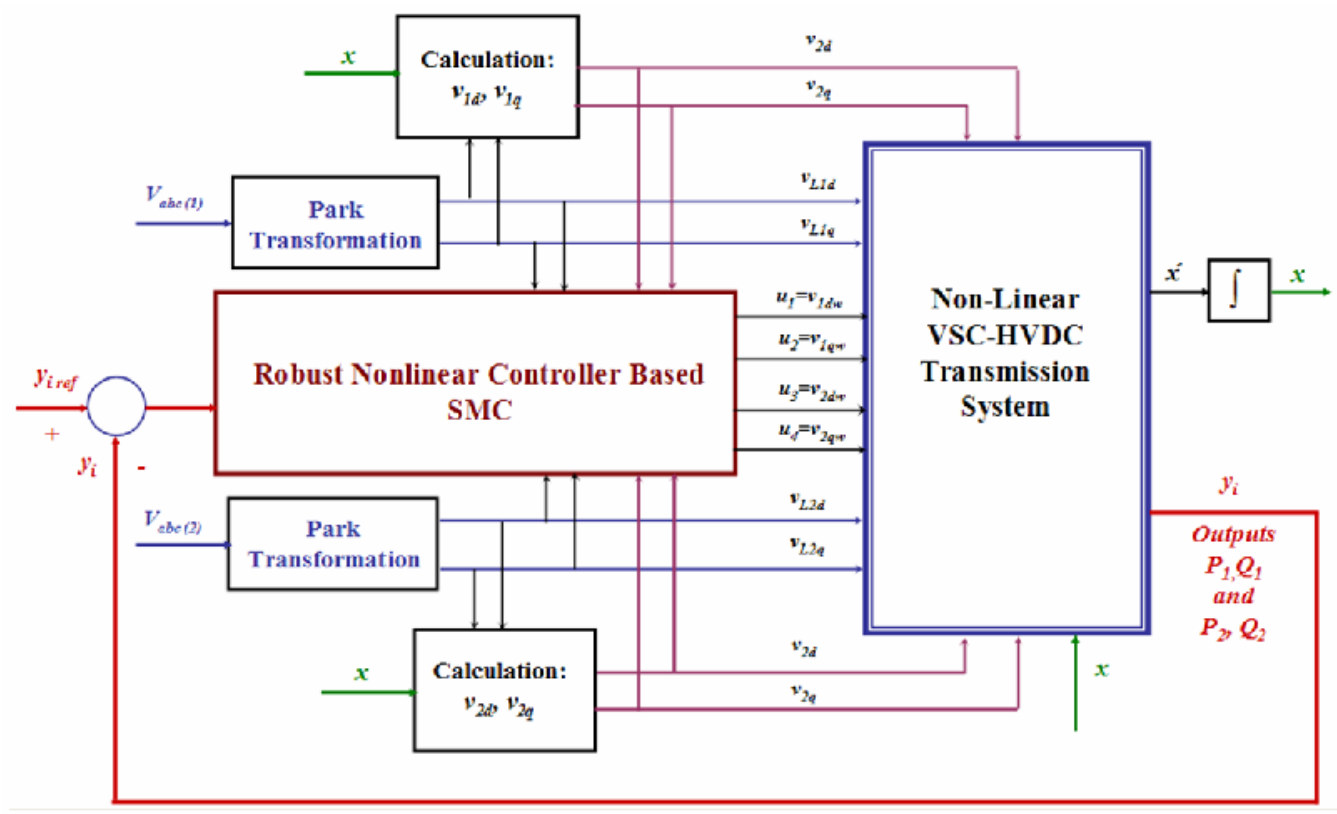

Figure (5): Overall HVDC Light system schematic diagram with Controller (1) 


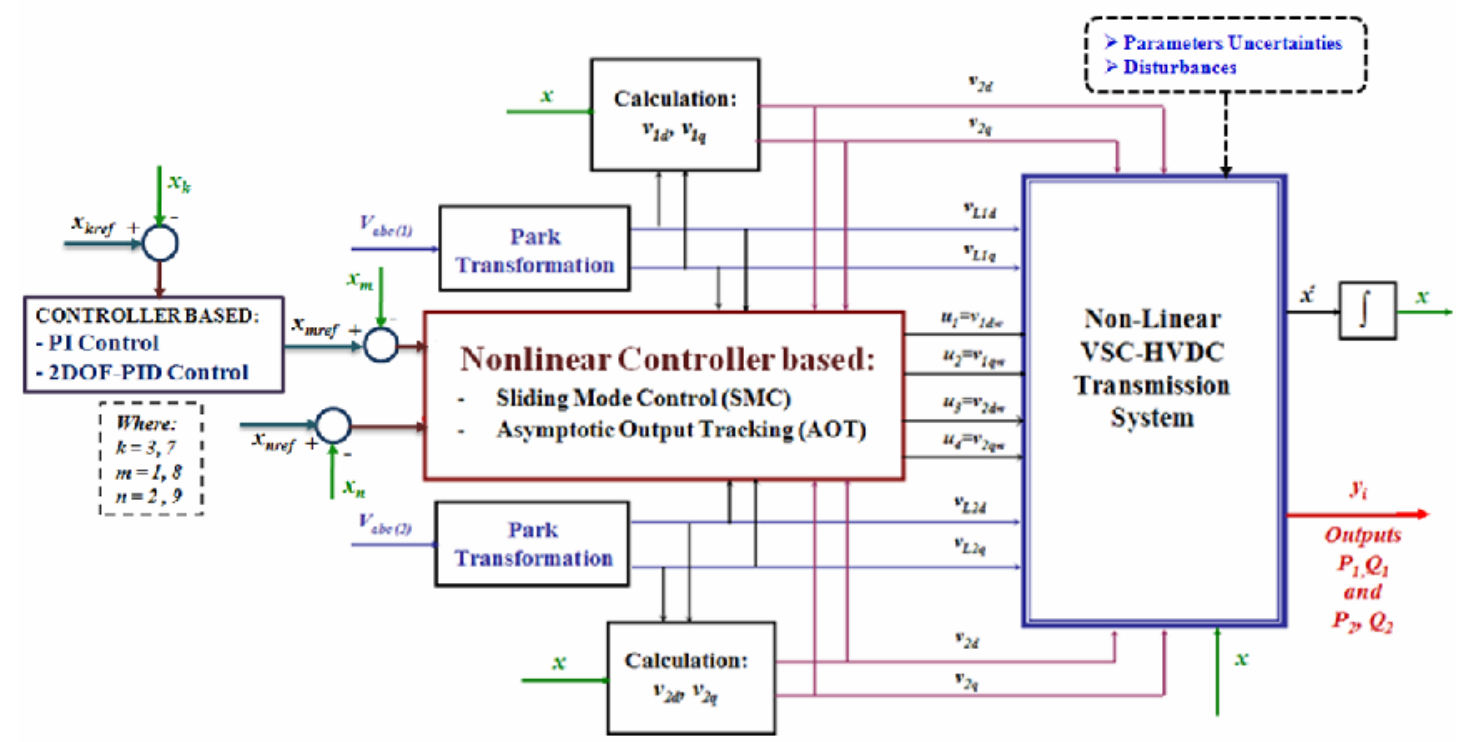

Figure (6): Overall HVDC Light system schematic diagram with Controller (2)

Controller (2): in which the $d-q$ current reference signals are generated using a supplementary PI controller (Controller 2:(a) and (b)) or an extra feedback 2DOF-PID controller (Controller 2:(c)) as depicted in Fig. 6. The main controller based SMC makes use of these signals to control the corresponding active and reactive powers. Evidently, the DC voltages at both DC link sides have been governed via the auxiliary controllers.

The PID controller, as shown in (19), has been described by [30]:

$\mathrm{u}(\mathrm{t})=\mathrm{K}_{\mathrm{p}}\left(\mathrm{e}(\mathrm{t})+\frac{1}{\mathrm{~T}_{\mathrm{i}}} \int_{0}^{\mathrm{t}} \mathrm{e}(\tau) \mathrm{d} \tau+\mathrm{T}_{\mathrm{d}} \frac{\mathrm{de}(\mathrm{t})}{\mathrm{dt}}\right)$

Where, the measured process variable is $y$ and the reference variable is ref, thus, $\mathrm{e}$ is the control error given by (e=ref-y). The controller parameters are the proportional gain $\mathrm{K}_{\mathrm{p}}$, the integral time $T_{i}$, and the derivative time $T_{d}$. Practically, the term including $T_{d}$ is vanished for PI controllers.

For favorable PID controllers: the set point weighting, 2DOF, noise filtering and high frequency rolling off, and windup can be considered as given in Eq. (20) [30]:

$\mathrm{u}(\mathrm{t})=\mathrm{K}_{\mathrm{p}}\left(\operatorname{br}(\mathrm{t})-\mathrm{y}(\mathrm{t})+\frac{1}{\mathrm{~T}_{\mathrm{i}}} \int_{0}^{\mathrm{t}} \mathrm{e}(\tau) \mathrm{d} \tau+\mathrm{T}_{\mathrm{d}}\left(\mathrm{c} \frac{\mathrm{dr}(\mathrm{t})}{\mathrm{dt}}-\frac{\mathrm{dy}(\mathrm{t})}{\mathrm{dt}}\right)\right)$

The controller will be of type I-PD if $(b=0, c=0)$ or PI-D if $(b=1, c=0)$. The 2DOF-PID controller scheme with windup is shown explicitly in Fig. 7 [30]. The error signals inserted to the proposed auxiliary controller illustrated in Fig. 6 have been given by: 


$$
\begin{array}{ll}
\varepsilon_{\mathrm{m}}(\mathrm{x})=\mathrm{x}_{\mathrm{mref}_{\mathrm{r}}}-\mathrm{x}_{\mathrm{m}} & \mathrm{m}=1,8 \\
\varepsilon_{\mathrm{n}}(\mathrm{x})=\mathrm{x}_{\mathrm{n} \text { ref }}-\mathrm{x}_{\mathrm{n}} & \mathrm{n}=2,9
\end{array}
$$

Where; $x_{1}, x_{2}, x_{8}$ and $x_{9}$ correspond to the state currents $i_{L 1 d}, i_{L 1 q}, i_{L 2 d}$, and $i_{L 2 q}$ respectively, on which the systems' active and reactive powers' at the DC terminals of the HVDC Light systems depend as mentioned in Eqs. (13)-(16).

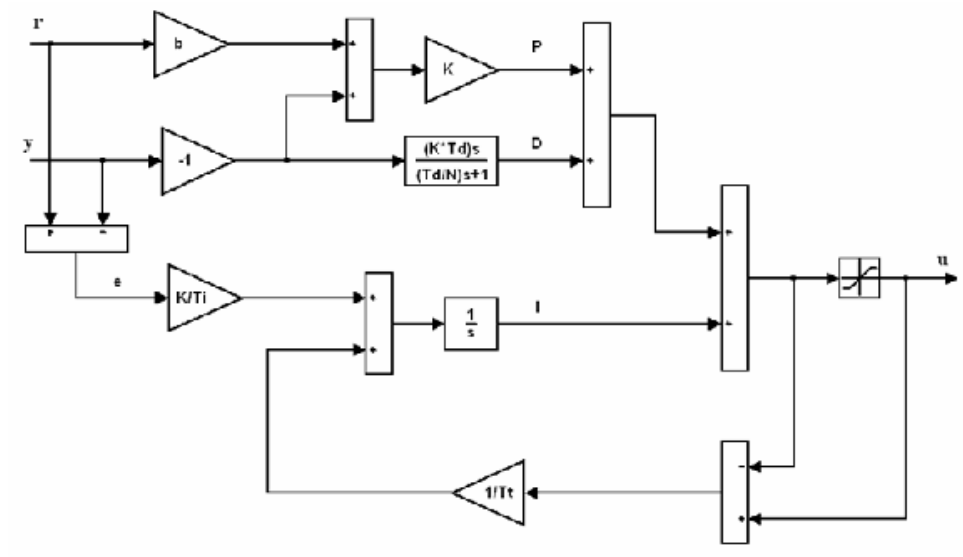

Figure (7): 2DOF-PID controller block diagram with windup

Likewise, to ensure stability, Lyapunov energy function candidate with

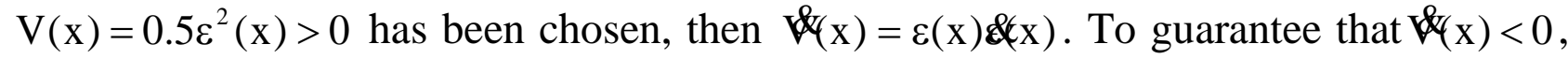
a function among the set listed in (18) for $(x)$, with mandatory positive tuning gains $\mathrm{K}_{1}$ and $\mathrm{K}_{2}$, has been selected. The higher the positive tuning gains, the faster the speed of convergence will be. The Asymptotic Output Tracking (AOT) Control can be replaced the SMC by supposing $\mathrm{K}_{2}$ equals zero in Eq. (18).

\section{Simulation Hypotheses and Results}

To validate the overall steady state model using the proposed control strategies, simulation studies of the system shown in Fig. 2 have been executed with the operating conditions and the tuning gains demonstrated in Appendix B.

To evaluate the proposed nonlinear controllers' effectiveness, the system states and output powers behaviors have been pointed out using both control methodologies. It can be verified which methodology has been better adopted to deal with HVDC Light systems. Comparisons have been made considering the system's normal operating conditions to show the advantages of both nonlinear controllers.

Controller 1. The system active and reactive power responses, supposing normal operating conditions, have been given in Fig. 8. Obviously, controller 1 is very successful considering different positive values for $\mathrm{K}$. The system behaviors have been 
improved regardless the value of $\mathrm{K}$. However, the higher the tuning gain $\mathrm{K}$ is, the smaller the settling time and the better the speed of convergence will be.
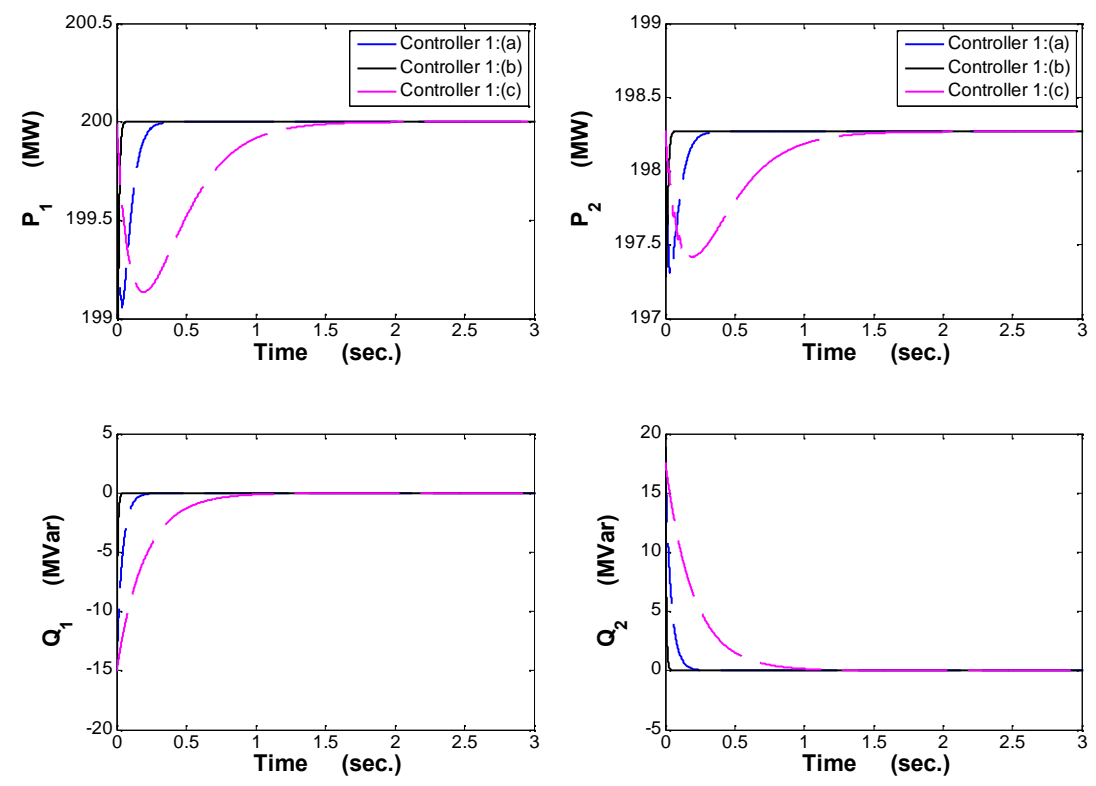

Figure (8): Active and reactive power behaviours on both AC sides of HVDC Light using Controller 1 with: (a) $K=25$ (b) $K=150$ (c) $K=5$

Controller 2. Using such a controller, the goal of controlling the active and reactive power and governing the DC voltage of the HVDC Light system to their aforesaid rated values has been fulfilled. The states and output behaviors of the system are depicted in Figs. 9 to 11 using an alternative control methodology in which the SMC is employed with an auxiliary PI or 2DOF-PID controller that govern the DC voltage and generate the $d-q$ currents. Active and reactive powers control, as noticed from Eqs. (13)-(16), has been ensured by controlling these currents. Acceptable states and output responses have been obtained when an extra PI controller has been used. Raising the integral gain $\mathrm{K}_{\mathrm{i}}$ up to 5000 instead of 700 will enhance the system stability as the oscillations damping has been ameliorated and the settling time has become shorter ( $\approx 0.2 \mathrm{sec}$ instead of $0.5 \mathrm{sec}$ ).

However, when an additional 2DOF-PID controller is provided instead of the PI one, undesirable damping oscillations, non-recommendable overshoots and higher time response have been existed. Another drawback of controller 2 is that: although the main objective of maintaining DC-bus voltage at its rated $300 \mathrm{kV}$ and controlling the active power to approximately $200 \mathrm{MW}$ have been noticeably achieved, the corresponding steady state values for $\mathrm{Q}_{1}$ and $\mathrm{Q}_{2}$ have been 10 MVar and -10 MVAR respectively. An acceptable power factor of 0.9987 (which is not exactly unity) has been obtained because of the slightly small steady state errors in the $d$-q currents generated by the auxiliary controller. 

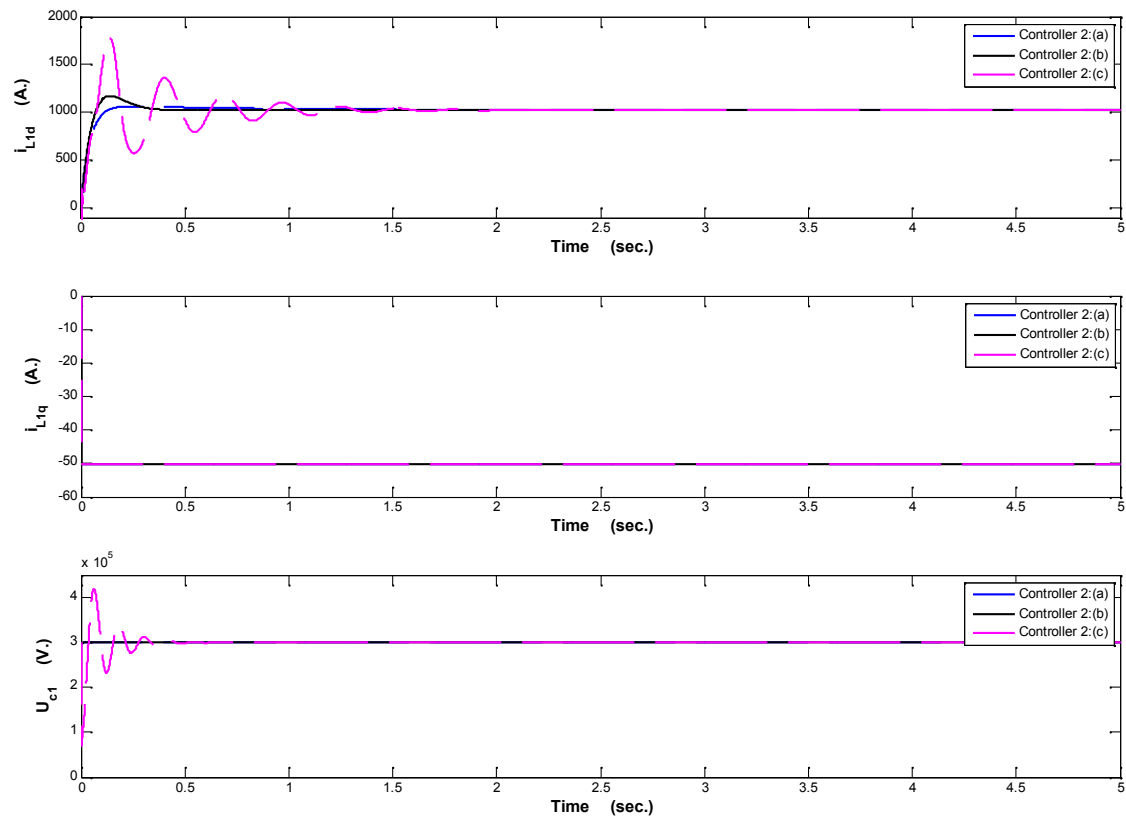

Figure (9): Currents and DC voltage behaviors of side 1 using Controller 2 with: (a) PI controller with $K_{i}=700$, (b) PI controller with $K_{i}=5000$ (c) 2DOF-PID controller
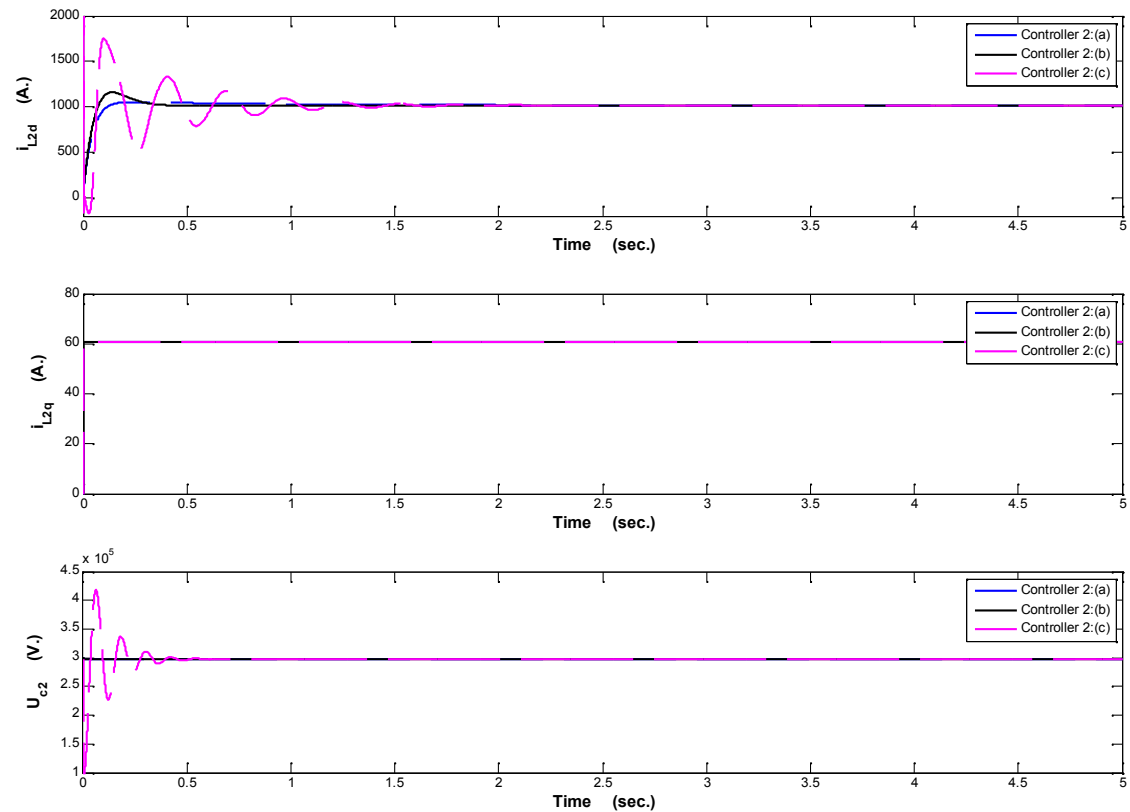

Figure (10): Currents and DC voltage behaviors of side 2 using Controller 2 with: (a) PI controller with $K_{i}=700$, (b) PI controller with $K_{i}=5000$ (c) 2DOF-PID controller Explicitly, the desired controller 1 based SMC is significantly effective and becomes a relatively successful choice compared to controller 2 especially with higher positive tuning gains despite the absence of the auxiliary controller. The undesirable reactive 
powers have become zeros. Significant oscillation damping and better convergence time are provided. Precisely, the system's dynamic behavior is enhanced. In addition, no complexity existed in obtaining the control laws and it can be easily implemented.
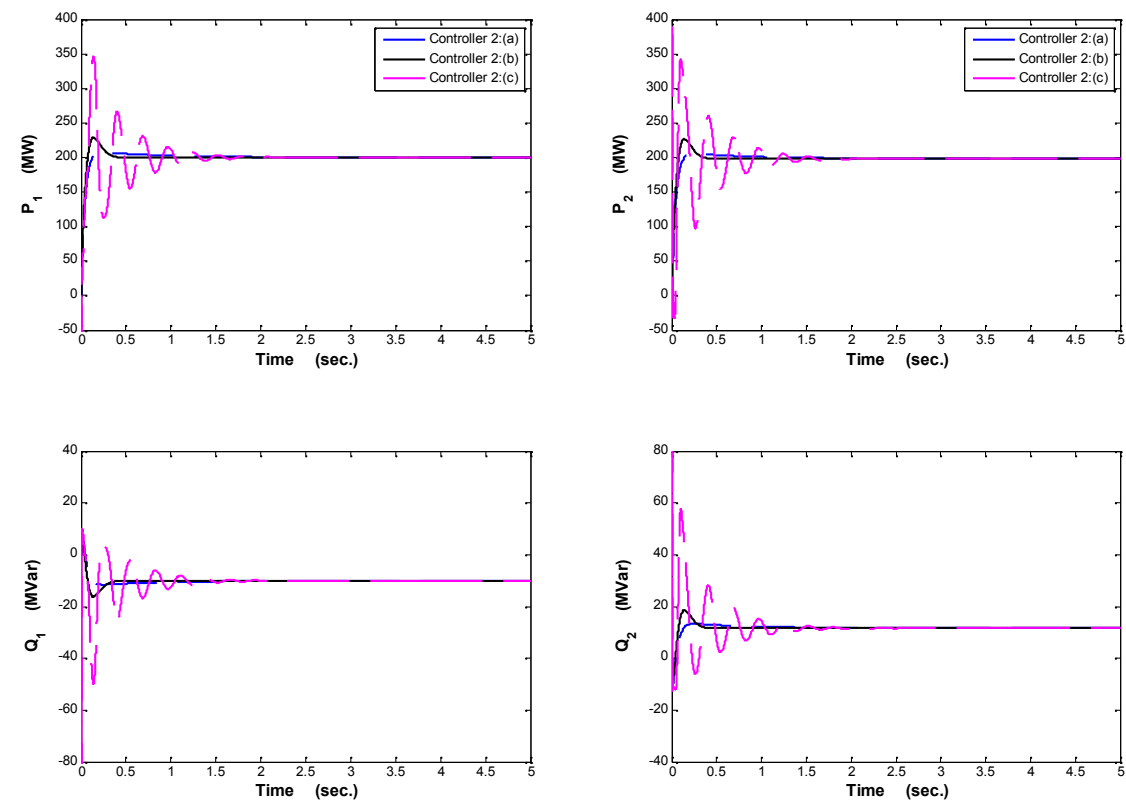

Figure (11): Active and reactive power behaviors using Controller 2 and: (a) PI controller with $K_{i}=700$, (b) PI controller with $K_{i}=5000$ (c) 2 DOF-PID controller

To ensure the robustness of the controller 1 which gives better performance under normal operating conditions and in the presence of uncertainties of 5\%,15\% and $25 \%$ considered in the DC link resistance. This type of uncertainty may be resulted due to the flow of high currents in the DC link. In the presence of resistance uncertainty and supposing active power reference variations, the active and reactive power responses are displayed in Fig. 12. The active power reference has been 200 MW, 240 MW and 160 MW respectively with a time interval of 2 seconds for each. Controller 1 has gone well towards successfully controlling the reactive powers to zero values and governing the DC voltage to its rated value. The active power responses have followed their prescribed reference values with acceptable small steady state errors. The absolute values of these steady state errors have been listed in Table 1. Clearly, supposing resistance uncertainty of $25 \%$, the maximum absolute steady state errors (in percentage) have been $1.47 \%$ and $2.19 \%$ for active power references of $240 \mathrm{MW}$ and $160 \mathrm{MW}$ respectively which seems to be acceptable. These steady state errors can be avoided easily by making use of an additional integral action in the controller.

Under the same operating conditions, it is important to evaluate how effective the controller 1 will be if interconnecting two AC networks located $200 \mathrm{~km}, 500 \mathrm{~km}$ and $1000 \mathrm{~km}$ apart. Simulation has been done for these different DC line lengths 
respectively. To perform such cases, the DC link parameters as resistances, inductances and capacitances have been increased to 2, 5 and 10 times the original respectively (i.e. changing the DC link resistance is enough as the effect of both the line inductance and the capacitive reactance is negligible with respect to the resistance because the rate of change of the currents and voltages is vanished in DC).
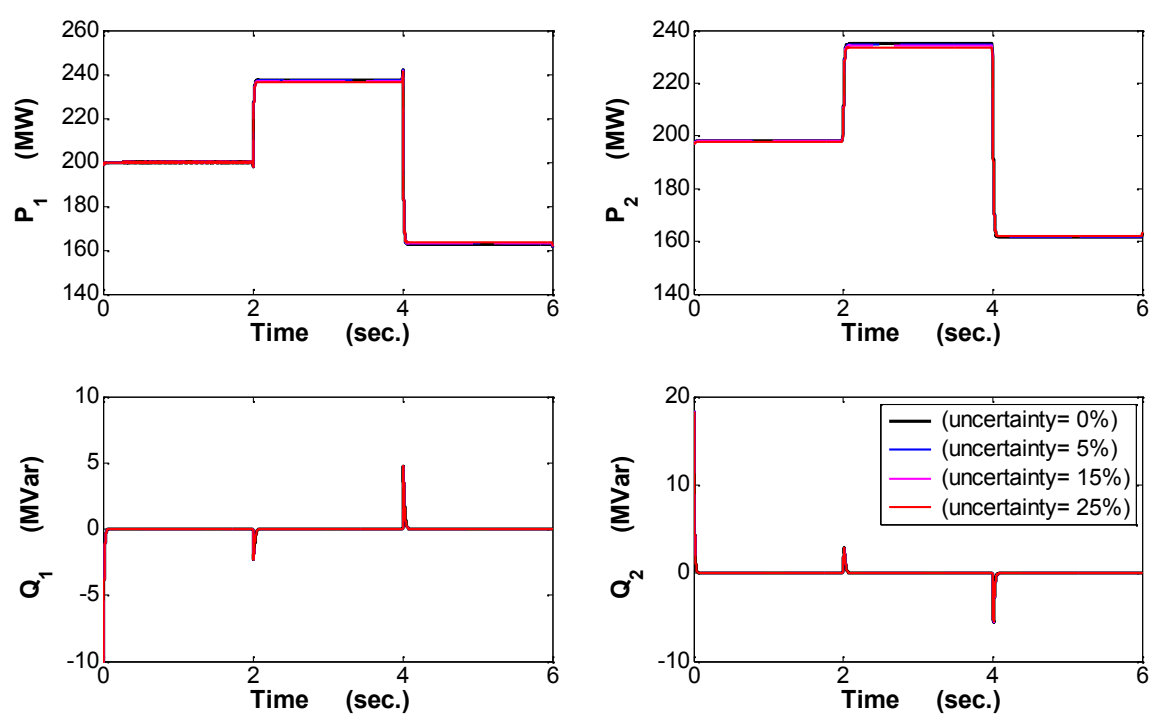

Figure (12): Active and reactive power behaviors on both AC sides of HVDC Light using Controller 1 considering resistance uncertainty

Table (1): Resistance uncertainty effect on the active power $P_{1}$

\begin{tabular}{cccc}
\hline \hline \multirow{2}{*}{$\begin{array}{c}\text { Uncertainty } \\
(\mathrm{R})\end{array}$} & Case 1 & Case 2 & Case 3 \\
& $\begin{array}{c}\mathrm{P}_{1}=200 \mathrm{MW} \\
\left|\mathrm{e}_{\mathrm{ss}}\right| \%\end{array}$ & $\begin{array}{c}\mathrm{P}_{1}=240 \mathrm{MW} \\
\left|\mathrm{e}_{\mathrm{ss}}\right| \%\end{array}$ & $\begin{array}{c}\mathrm{P}_{1}=160 \mathrm{MW} \\
\left|\mathrm{e}_{\mathrm{ss}}\right| \%\end{array}$ \\
\hline 0 & $\approx 0$ & 1.12 & 1.75 \\
\hline $5 \%$ & $\approx 0$ & 1.17 & 1.87 \\
\hline $15 \%$ & $\approx 0$ & 1.29 & 2.06 \\
\hline $25 \%$ & $\approx 0$ & 1.47 & 2.19 \\
\hline \hline
\end{tabular}

$\left|\mathrm{e}_{\mathrm{ss}}\right|:$ the absolute steady state error

Definitely, Figs. 13 and 14 illustrate the capability of the proposed controller to control the active and reactive power in both AC sides of the HVDC, and, to govern the DC voltages on both sides of the DC link supposing various distances separating the AC stations besides a reference variation of $+20 \%$ and $-20 \%$ of the rated power (200 MW) each 2 seconds. In Fig. 13, although the DC link lengths have been changed, the reactive power seems to be always zero which results in desired unity power factors on the AC sides of the HVDC. On the other hand, the active power tracks precisely its rated value 
for the first 2 seconds for all different lengths proposed then acceptable deviations from the rated power have been resulted in the following 4 seconds. Adequate absolute steady state errors of the active power in different periods have been drawn as presented in Table 2. Admissible $D C$ voltages $\mathrm{U}_{\mathrm{c} 1}, \mathrm{U}_{\mathrm{cc}}$ and $\mathrm{U}_{\mathrm{c} 2}$ have been acquired and exhibited for different DC link lengths. $U_{\mathrm{cl}}$ always tracks the $300 \mathrm{kV}$ reference whatever the DC link length are. However, $\mathrm{U}_{\mathrm{cc}}$ and $\mathrm{U}_{\mathrm{c} 2}$ have been altered, due to different voltage drop and power losses resulted, as illustrated in Fig. 14. The longer the DC links, the greater the voltage drop and power losses which lead to lower values of $U_{c c}$ and $U_{c 2}$.

Table (2): Effect of DC line length on the active power $P_{1}$

\begin{tabular}{cccc}
\hline $\begin{array}{c}\text { Line Length } \\
(\mathrm{L})\end{array}$ & $\begin{array}{c}\text { Case } 1 \\
\mathrm{P}_{1}=200 \mathrm{MW} \\
\left|\mathrm{e}_{\mathrm{ss}}\right| \%\end{array}$ & $\begin{array}{c}\text { Case } 2 \\
\mathrm{P}_{1}=240 \mathrm{MW} \\
\left|\mathrm{e}_{\mathrm{ss}}\right| \%\end{array}$ & $\begin{array}{c}\text { Case 3 } \\
\mathrm{P}_{1}=160 \mathrm{MW} \\
\left|\mathrm{e}_{\mathrm{ss}}\right| \%\end{array}$ \\
\hline $100 \mathrm{Km}$ & $\approx 0$ & 3.79 & 5.81 \\
\hline $200 \mathrm{Km}$ & $\approx 0$ & 6.46 & 9.81 \\
\hline $500 \mathrm{Km}$ & $\approx 0$ & 10.46 & 15.75 \\
\hline $1000 \mathrm{Km}$ & $\approx 0$ & 12.96 & 19.43 \\
\hline \hline
\end{tabular}
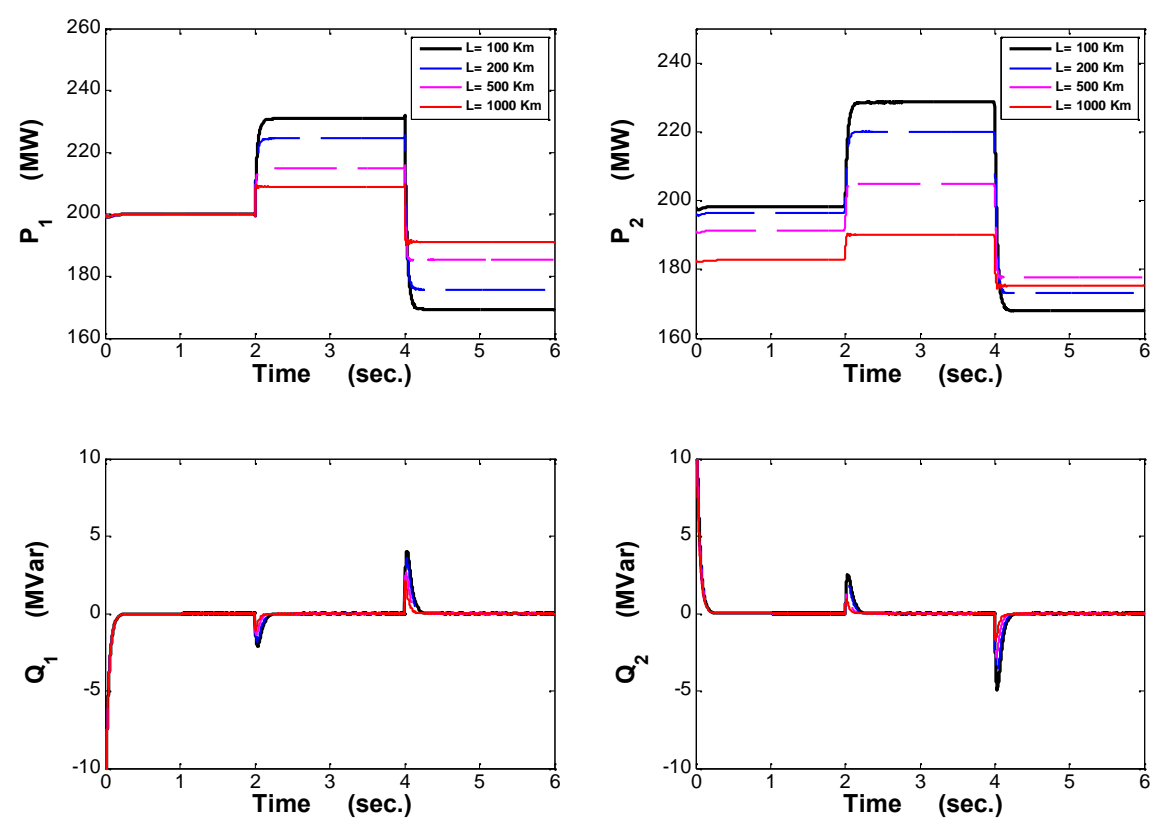

Figure (13): Active and reactive power behaviors using Controller 1 with:

(a) $L=100$, (b) $L=200$, (c) $L=500$, (d) $L=1000$ 

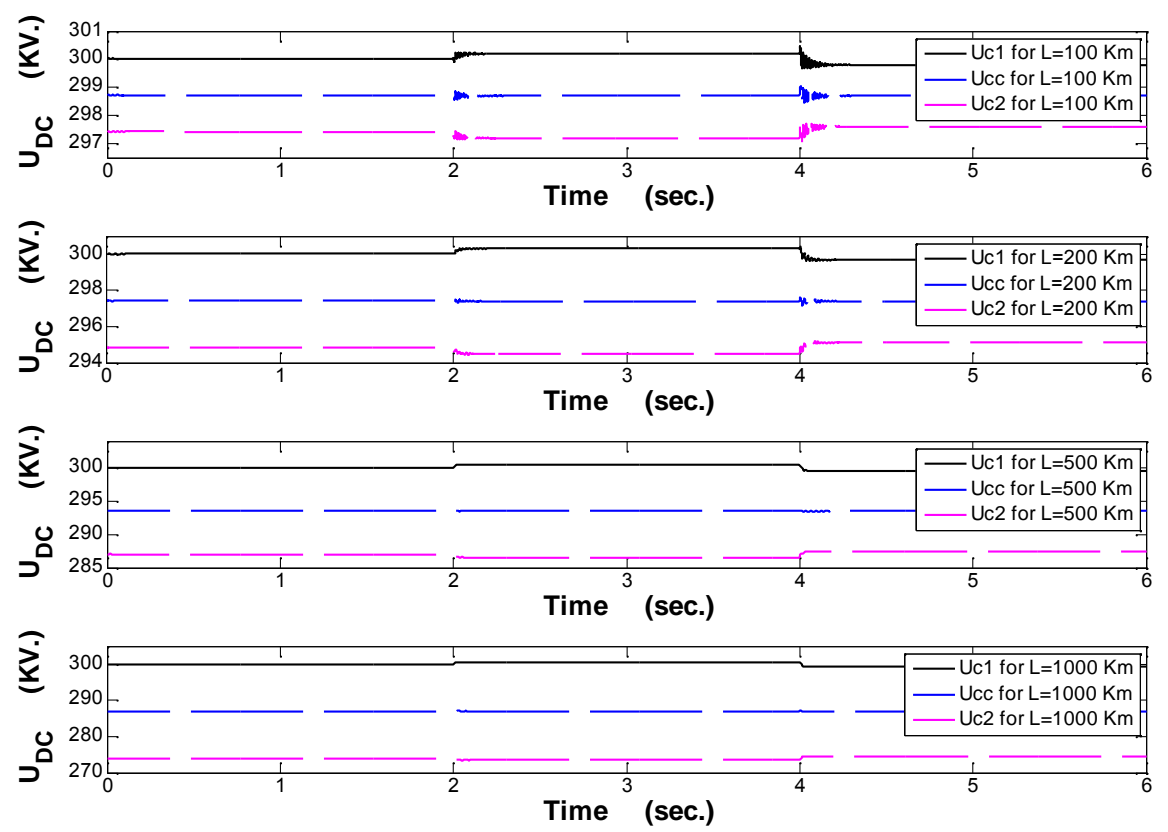

Figure (14): $D C$ voltage over the DC link $\left(U_{c 1}, U_{c c}, U_{c 2}\right)$ using Controller 1 with: (a) $L=100$, (b) $L=200$, (c) $L=500$, (d) $L=1000$

Distinctly, the proposed nonlinear controllers have been profitably used, not only during the normal operating conditions or in the presence of parameters uncertainties but also for different DC link lengths, to enhance the system behavior. Moreover, its robustness has been assessed. The results clearly clarify the controllers' flexibility and feasibility towards stabilizing the system and improving its performance.

\section{Conclusion}

For HVDC Light transmission links, where parameters uncertainties are involved in the plant operation, it is important to design control strategies which are robust under all possible normal and abnormal situations. After developing the system's mathematical model, the control action based SMC can be directly expressed as any function of the error. Using the Lyapunov energy function, the proposed methods guarantee robustness as well as tracking performance. Simply, two different nonlinear controllers based SMC are applied. The MATLAB simulation results ensure that the proposed controllers provide relatively high stability margins, significantly good robustness and notably better performance. Additionally, the superiority of the controller based on SMC only over the other (SMC with a PI or 2DOF-PID) is displayed. The responses can be further improved by optimizing the SMC controller gains.

The future work will comprise the validation of the proposed controllers using EMTP simulator in the presence of faults and the application of HVDC Light (with more detailed model) to larger and more complex power systems. 


\section{$\underline{\text { Appendix }}$}

\section{Appendix A}

The nonlinear control law using SMC can be deduced by differentiating Eqs. (13)-(16) and then the substitution of the state equations Eqs. (8)-(12) into the resulted equations. By solving simultaneously the outcome equations for the control inputs, the following nonlinear control laws are formulated:

$$
\begin{aligned}
& \mathrm{u}_{1}=\frac{\mathrm{v}_{1 \mathrm{~d}}\left[\left(\frac{2}{3}\right)-\alpha_{1}\right]+\mathrm{v}_{1 \mathrm{q}}\left[\left(\frac{2 \mathrm{~L}_{\mathrm{L}}}{3}\right)-\alpha_{2}\right]}{\left[\left(\frac{-1}{2 \mathrm{~L}_{\mathrm{L} 1}}\right) \mathrm{x}_{3}\left(\mathrm{v}_{1 \mathrm{~d}}^{2}+\mathrm{v}_{1 \mathrm{q}}^{2}\right)\right]} \\
& \mathrm{u}_{2}=\frac{\mathrm{v}_{1 \mathrm{q}}\left[\left(\frac{2 \mathrm{~L}}{3}\right)-\alpha_{1}\right]-\mathrm{v}_{\mathrm{ld}}\left[\left(\frac{2 \mathrm{~L}}{3}\right)-\alpha_{2}\right]}{\left[\left(\frac{-1}{2 \mathrm{~L}_{\mathrm{L} 1}}\right) \mathrm{x}_{3}\left(\mathrm{v}_{1 \mathrm{~d}}^{2}+\mathrm{v}_{1 \mathrm{q}}^{2}\right)\right]} \\
& \mathrm{u}_{3}=\frac{\mathrm{v}_{2 \mathrm{~d}}\left[\left(\frac{2 \&}{3}\right)-\beta_{1}\right]+\mathrm{v}_{2 \mathrm{q}}\left[\left(\frac{2 \mathrm{H}_{4}}{3}\right)-\beta_{2}\right]}{\left[\left(\frac{1}{2 \mathrm{~L}_{\mathrm{L} 2}}\right) \mathrm{x}_{7}\left(\mathrm{v}_{2 \mathrm{~d}}^{2}+\mathrm{v}_{2 \mathrm{q}}^{2}\right)\right]} \\
& \mathrm{u}_{4}=\frac{\mathrm{v}_{2 \mathrm{q}}\left[\left(\frac{2}{3}\right)-\beta_{1}\right]-\mathrm{v}_{2 \mathrm{~d}}\left[\left(\frac{2 \mathrm{~L}_{4}}{3}\right)-\beta_{2}\right]}{\left[\left(\frac{1}{2 \mathrm{~L}_{\mathrm{L} 2}}\right) \mathrm{x}_{7}\left(\mathrm{v}_{2 \mathrm{~d}}^{2}+\mathrm{v}_{2 \mathrm{q}}^{2}\right)\right]}
\end{aligned}
$$

where,

$$
\begin{aligned}
& \alpha_{1}=\mathrm{v}_{1 \mathrm{~d}}\left[\left(\frac{-\mathrm{R}_{\mathrm{L} 1}}{\mathrm{~L}_{\mathrm{L} 1}} \mathrm{x}_{1}+\mathrm{w}_{1} \mathrm{x}_{2}+\frac{1}{\mathrm{~L}_{\mathrm{L} 1}} \mathrm{z}_{1}\right]+\mathrm{v}_{1 \mathrm{q}}\left[-\mathrm{w}_{1} \mathrm{x}_{1}+\left(\frac{-\mathrm{R}_{\mathrm{L} 1}}{\mathrm{~L}_{\mathrm{L} 1}}\right) \mathrm{x}_{2}+\frac{1}{\mathrm{~L}_{\mathrm{L} 1}} \mathrm{z}_{2}\right]\right. \\
& \alpha_{2}=\mathrm{v}_{1 \mathrm{q}}\left[\left(\frac{-\mathrm{R}_{\mathrm{L} 1}}{\mathrm{~L}_{\mathrm{L} 1}} \mathrm{x}_{1}+\mathrm{w}_{1} \mathrm{x}_{2}+\frac{1}{\mathrm{~L}_{\mathrm{L} 1}} \mathrm{z}_{1}\right]-\mathrm{v}_{\mathrm{ld}}\left[-\mathrm{w}_{1} \mathrm{x}_{1}+\left(\frac{-\mathrm{R}_{\mathrm{L} 1}}{\mathrm{~L}_{\mathrm{L} 1}}\right) \mathrm{x}_{2}+\frac{1}{\mathrm{~L}_{\mathrm{L} 1}} \mathrm{z}_{2}\right]\right. \\
& \beta_{1}=\mathrm{v}_{2 \mathrm{~d}}\left[\left(\frac{-\mathrm{R}_{\mathrm{L} 2}}{\mathrm{~L}_{\mathrm{L} 2}}\right) \mathrm{x}_{8}+\mathrm{w}_{2} \mathrm{x}_{9}-\frac{1}{\mathrm{~L}_{\mathrm{L} 2}} \mathrm{z}_{3}\right]+\mathrm{v}_{2 \mathrm{q}}\left[-\mathrm{w}_{2} \mathrm{x}_{8}+\left(\frac{-\mathrm{R}_{\mathrm{L} 2}}{\mathrm{~L}_{\mathrm{L} 2}}\right) \mathrm{x}_{9}-\frac{1}{\mathrm{~L}_{\mathrm{L} 2}} \mathrm{z}_{4}\right] \\
& \beta_{2}=\mathrm{v}_{2 \mathrm{q}}\left[\left(\frac{-\mathrm{R}_{\mathrm{L} 2}}{\mathrm{~L}_{\mathrm{L} 2}}\right) \mathrm{x}_{8}+\mathrm{w}_{2} \mathrm{x}_{9}-\frac{1}{\mathrm{~L}_{\mathrm{L} 2}} \mathrm{z}_{3}\right]-\mathrm{v}_{2 \mathrm{~d}}\left[-\mathrm{w}_{2} \mathrm{x}_{8}+\left(\frac{-\mathrm{R}_{\mathrm{L} 2}}{\mathrm{~L}_{\mathrm{L} 2}}\right) \mathrm{x}_{9}-\frac{1}{\mathrm{~L}_{\mathrm{L} 2}} \mathrm{z}_{4}\right]
\end{aligned}
$$




\section{Appendix B}

The overall system's operating conditions and tuning gains:

Frequency for both AC networks: $\mathrm{f}_{1}=50 \mathrm{~Hz}, \mathrm{f}_{2}=60 \mathrm{~Hz}$

Equivalent resistance of $\mathrm{AC}$ generator and transmission line and, the equivalent inductance of $\mathrm{AC}$ generator and transmission line for both sides:

$\mathrm{R}_{\mathrm{L} 1}=0.01 \Omega, \mathrm{L}_{\mathrm{L} 1}=40 \mathrm{mH}$ and $\mathrm{R}_{\mathrm{L} 2}=0.01 \Omega, \mathrm{L}_{\mathrm{L} 2}=40 \mathrm{mH}$

Rated active power for both sides: $\mathrm{P}_{\mathrm{L} 1}=\mathrm{P}_{\mathrm{L} 2}=200 \mathrm{MW}$

Rated DC-voltage for both sides: $\mathrm{U}_{\mathrm{c} 1}=\mathrm{U}_{\mathrm{c} 2}=300 \mathrm{kV}$

DC cable resistances and inductances:

$\mathrm{R}_{\mathrm{cl}}=\mathrm{R}_{\mathrm{cl}}=1.95 \Omega$, and $\mathrm{L}_{\mathrm{cl}}=\mathrm{L}_{\mathrm{cl}}=11.5 \mathrm{mH}$

DC shunt capacitors, $\mathrm{C}_{1}=\mathrm{C}_{2}=20 \quad \mathrm{~F}, \mathrm{C}_{\mathrm{c}}=16 \quad \mathrm{~F}$

Controller 1: tuning parameters for both sides are:

Case (a): $K_{1}=K_{2}=K=25$

Case (b): $\mathrm{K}_{1}=\mathrm{K}_{2}=\mathrm{K}=150$

Case (c): $\mathrm{K}_{1}=\mathrm{K}_{2}=\mathrm{K}=5$

Controller 2: tuning parameters for both sides are:

Case (a): $K_{\mathrm{p}}=500, \mathrm{~K}_{\mathrm{i}}=700, \mathrm{~K}_{1}=1500, \mathrm{~K}_{2}=150$

Case (b): $K_{p}=500, K_{i}=5000, K_{1}=1500, K_{2}=150$

Case (c): $b=0, N=20, K_{p}=50, T_{d}=0.05, T_{i}=0.005$

\section{$\underline{\text { References }}$}

[1] I. M. de Algeria, J. L. Martin, I. Kortabarria, J. Andreu and P. I. Ereno, Transmission Alternatives for Offshore Electrical Power, Presented at Renewable and Sustainable Energy Review, 2008. [Online] www.elsevier.com/locate/rser

[2] S. Meier, Novel Voltage Source Converter Based HVDC Transmission System for Offshore Wind Farms, Doctoral Thesis. Stockholm, Sweden: Royal Institute of Technology; 2005.

[3] C. Du, A. Sannino, and M. H. J. Bollen, Analysis of the Control Algorithms of Voltage-Source Converter HVDC, Presented at IEEE/Power Tech Conference, Russia, P. 1-7, 2005.

[4] Y. Jiang-Hafner, H. Duchen, K. Linden, M. Hyttinen, P. F. de Toledo, T. Tulkiewicz, A. K. Skytt, and H. Bjorklund, Improvement of Subsynchronous Torsional Damping using VSC HVDC, Presented at PowerCon, China, 2002.

[5] L. Weimers, New Markets Need New Technology, Presented at PowerCon Conference, Australia, 2000.

[6] G. Reed, R. Pape, and M. Takeda, Advantages of Voltage Sourced Converter (VSC) based Design Concepts for FACTS and HVDC-link Applications, Proc. of IEEE/PES Meeting, vol. 3, P. 1816-1821, 2003. 
[7] L. Stendius and K. Eriksson, HVDC Light - An Excellent Tool For City Center Infeed, Presented at PowerGen Conference, Singapore, 1999.

[8] H. F. Latorre, M. Ghandhari, and L. Söder, Active and Reactive Power Control of a VSC-HVDC, in Electric Power Systems Research, vol. 78, P. 1756-1763, 2008.

[9] G. Xu, J. Wang, and C. Chen, Feedback Stabilization for AC/DC Power System with Nonlinear Loads, in Electric Power Systems Research, Vol. 74, P. 247-255, 2005.

[10] H. Liu, Z. Xu, and Z. Gao, A Control Strategy for Three-level VSC-HVDC System, Presented at IEEE/PESS Meeting, Vol. 1, P. 480-485, 2002.

[11] Y.-y. Hsu, and L. Wang, Damping of a Parallel ac-dc Power System using PID Power System Stabilizers and Rectifier Current Regulators, IEEE Trans. Energy Conversion, Vol. 3, P. 540-547, 1988.

[12] S.M. Badran, and M.A. Choudhry, Design of Modulation Controllers for ac/dc Power Systems, IEEE Trans. Power Syst., Vol. 8, P. 1490-1496, 1993.

[13] L. Chen, H. Tanaka, K. Katou, and Y. Nakamura, Stability Analysis for Digital Controls of Power Systems, Electric Power Systems Research, Vol. 55, P. 79-86, 2000.

[14] A. Colbia-Vega, J. de León-Morales, L. Fridman, O. Salas-Peña, and M.T. Mata-Jiménez, Robust Excitation Control Design using Sliding-Mode Technique for Multimachine Power Systems,Electric Power Systems Research, Vol. 78, (Issue 9): P. 1627-1634, September 2008.

[15] K.W.V. To, and A.K. David, Multivariable adaptive control of AC-DC systems, IEE Proc.-Gener. Transm. Distrib., Vol. 141 (6), P. 658-664, 1994.

[16] A. A. Ghandakly, and A.M. Farhoud, A Parametrically Optimized Selftuning Regulator for Power System Stabilizers, IEEE Trans. Power Syst., Vol. 7 (3), P. 1245-1250, 1992.

[17] V.G.D.C. Samarasinghe, and N.C. Pahalawaththa, Stabilization of a Multi-Machine Power System using Nonlinear Robust Variable Structure Control, Electric Power Systems Research, Vol. 43, P. 11-17, 1997.

[18] A. Isidori, Nonlinear Control Systems, Springer Verlag, New York, 1995.

[19] Hoon Lee, and Vadim I. Utkin, Chattering Suppression Methods in Sliding Mode Control Systems, Annual Reviews in Control, Vol. 31, (Issue 2): P. 179-188, 2007.

[20] H. Khalil, Nonlinear Systems, (Prentice-Hall, 1996).

[21] J. V. Hung, W. Gco, and J. C. Hung, Variable Structure Control: A Survey, IEEE Trans. Ind. Electron., Vol. 40: P. 2-22, 1993.

[22] F. Zhou, and D. G. Fisher, Continuous sliding mode control, Int. J. Control, Vol. 55, P. 313-327, 1992.

[23] M. Durrant, H. Werner and K. Abbott, Synthesis of Multi-objective Controllers for a VSC HVDC Terminal using LMIs, $43^{\text {rd }}$ IEEE Conference on Decision and Control, Vol. 4, P. 4473-4478, 2004. 
[24] M. Durrant, H. Werner, and K. Abbott, A Comparison of Current Controller Designs for VSC-HVDC, $10^{\text {th }}$ European Conference on Power Electronics and Applications, September 2003.

[25] H. Cherouat, H. Siguerdidjane, J.-L. Thomas and S. Poullain, Sliding Modes Control of VSC-HVDC Transmission Systems, EPE Proceedings, Toulouse, September 2003.

[26] H. S. Ramadan, H. Siguerdidjane and M. Petit, Robust Nonlinear Control Strategy for HVDC Light Transmission Systems Technology, $34^{\text {th }}$ IEEE- IECON CD Proceedings, USA, 2008.

[27] H. S. Ramadan, H. Siguerdidjane, M. Petit and R. Kaczmarek, Robust VSC-HVDC Systems Based on Sliding Mode Control, $2^{\text {nd }}$ Int. Conf. on Elec Eng. Design and Tech., ICEEDT CD Proceedings, Tunisia, 2008.

[28] H. S. Ramadan, H. Siguerdidjane and M. Petit, On the Robustness of VSC-HVDC Systems Controllers under Parameters Uncertainties, $40^{\text {th }}$ North American Power Symposium NAPS CD Proceedings, Calgary, Canada, 2008.

[29] H. S. Ramadan, H. Siguerdidjane and M. Petit, A Robust Stabilizing Nonlinear Control Design for VSC-HVDC Systems: A Comparative Study, IEEE International Conference of Industrial Technology, ICIT CD Proceedings, Australia, 2009.

[30] Karl J. Astrom, and Tore H. Hagglund, PID Controllers: Theory, Design and Tuning, (ISA:1995). 